\title{
Computer and robotic - assisted total knee arthroplasty: a review of outcomes
}

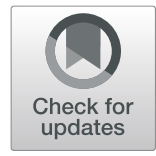

Jobe Shatrov ${ }^{1,2^{*}}$ (i) and David Parker ${ }^{1,2,3}$

\begin{abstract}
Background: Total knee arthroplasty (TKA) is a successful treatment for tricompartmental knee arthritis. Computer navigation and robotic-assisted-surgery (RAS) have emerged as tools that aim to help plan and execute surgery with greater precision and consistency. We reviewed the most current literature to describe the historical background and outcomes compared to conventional TKA.

Methods: A review and synthesis of the literature comparing the patient reported outcomes (PROM's) of RA TKA and computer-assisted (CA) TKA to conventional TKA was performed using the Preferred Reporting Items for Systematic Reviews and Meta-Analyses (PRISMA) guidelines.

Results: CAS TKA improves accuracy and consistency of implant position, and appears to provide a small improvement in PROMs and implant survival compared to conventional TKA. RTKA similarly improves implant accuracy compared to conventional techniques and early results suggest a similar small benefit in PROMs compared to conventional TKA. A strengthening trend is emerging showing CAS TKA has greatest benefit to implant survival in people under 65. RTKA survival analysis data is more limited and early results do not allow strong conclusions, however early trends are similar to CAS TKA.

Conclusion: Results for CAS-TKA show improvement in alignment, and early clinical outcomes have revealed promising results, with longer-term data and medium-term survival analysis recently emerging showing small benefits over conventional TKA. RTKA represents another phase of development. Early results show similar trends to that of CAS TKA with longer-term data still to come.
\end{abstract}

\section{Introduction}

Total knee arthroplasty (TKA) is a successful treatment for tricompartmental knee arthritis. Emphasis on optimal component sizing and alignment has led to increased use of tools that allow the delivery of preoperative plans and verification of intra-operative steps. Computer navigation and robotic-assisted-surgery (RAS) have emerged as tools that aim to help plan and execute surgery with greater precision and consistency, with the ultimate goal of improving patient outcomes in TKA.

Computer-assisted (CAS), or navigation-assisted refers to a device that has an interface that allows entry of anatomical

\footnotetext{
* Correspondence: jobeshatrov1@gmail.com

${ }^{1}$ Royal North Shore Hospital, St Leonards, Australia

${ }^{2}$ Sydney Orthopaedic Research Institute, Chatswood, Australia

Full list of author information is available at the end of the article
}

data, and then gives feedback to a surgeon regarding alignment of implants and overall alignment of the knee, but cannot be programmed to perform tasks. Multiple proprietary systems now exist and rapid technological advancements in computer processing power have stimulated development of robotic surgical systems. Robotic systems generally provide similar feedback to CAS systems, but can also be programmed to assist in the execution of certain surgical tasks.

Emerging data on the use of this technology in unicompartmental knee replacement (UKR) suggests an improvement in outcomes and survival at 2 years (2.8 vs $4.6 \%)$ compared to conventional techniques [1, 2], with shortterm results showing similar outcomes for both CAS and robotically assisted UKR [3]. There remains conflicting evidence as to whether increasing use of CAS and RAS results

\section{Springer Open}

() The Author(s). 2020 Open Access This article is licensed under a Creative Commons Attribution 4.0 International License, which permits use, sharing, adaptation, distribution and reproduction in any medium or format, as long as you give appropriate credit to the original author(s) and the source, provide a link to the Creative Commons licence, and indicate if changes were made. The images or other third party material in this article are included in the article's Creative Commons licence, unless indicated otherwise in a credit line to the material. If material is not included in the article's Creative Commons licence and your intended use is not permitted by statutory regulation or exceeds the permitted use, you will need to obtain permission directly from the copyright holder. To view a copy of this licence, visit http://creativecommons.org/licenses/by/4.0/. 
in either improved survivorship or patient reported outcomes measures (PROMs) following TKA.

The purpose of this review is to describe the historical background of robotic and computer-navigated systems used most commonly for total knee replacements, and review the most current available literature regarding outcomes compared to conventional TKA.

\section{Methods}

A review and synthesis of the literature comparing the PROMs of robotic-assisted total knee arthroplasty (RATK A) and CAS TKA to conventional TKA was performed using the Preferred Reporting Items for Systematic Reviews and Meta-Analyses (PRISMA) guidelines [4]. Primary outcome of interest was survivorship, with secondary outcome measures being PROMs.

\section{Search strategy}

The online databases Pubmed, Embase and CENTRAL (Cochrane Central Register of Controlled Trials) were searched. Publicly available registry data was also searched.

A search was performed on the 3.4.2020 using combined text and MESH terms: "Robotic Arm-assisted total knee arthroplasty", "robotic assisted total knee arthroplasty", "robotic knee arthroplasty", "robotic-assisted primary total knee arthroplasty," "computer assisted total knee arthroplasty", "computer assisted knee arthroplasty" and "computer assisted primary knee arthroplasty".

\section{Study selection and screening}

A total of 3157 abstracts were identified for further screening in two-stages. Abstracts were screened for data that compared PROMs or survivorship analysis of either CAS TKA or RATKA to conventional TKA. Full-text was downloaded and the article further assessed for eligibility based on inclusion criteria. Reference lists of selected articles were also searched for any additional articles.

\section{Computer-assisted total knee Arthroplasty}

A total of 2652 abstracts were identified from the initial search. After first stage screening a total of 135 full texts were assessed based on the listed eligibility criteria. 31 studies were found to be suitable for analysis in the final review of CAS TKA versus conventional TKA.

\section{Robotic-assisted total knee Arthroplasty}

A total of 705 abstracts were identified for further screening. After first stage screening a total of 34 full texts were assessed based on the listed eligibility criteria. 13 studies were found to be suitable for analysis in the final review of CAS TKA versus conventional TKA.

\section{Eligibility criteria}

Articles comparing outcomes of CAS TKA or RTKA to conventional TKA, published after the year 2000, adequate definition of robotic or computer assisted arthroplasty were included. Articles were excluded if they were not published in English, if data regarding survivorship, radiographic outliers or PROM's were not extractable from the results, operation after than total knee replacement performed, case reports or were duplicate studies (eg. publishing 5 year data with earlier article publishing 2 year data). Only level 1 to 3 studies according to AAOS grades of evidence were included in this review [5].

For the CAS TKA analysis only articles with minimum two-year follow-up were accepted. For RATKA, data at any follow-up period was accepted due to the published data in this area being relatively new.

\section{Historical perspective \\ Computer-assisted TKA}

The first navigated total knee replacement was performed in Grenoble in 1997 using an image-free navigation system [6], which used a kinematic model to determine the mechanical alignment of the limb. Later systems added anatomic landmarks from the knee and ankle to improve accuracy.

Most systems currently operate by use of cameras that allow entering of anatomical data via infra-red signal, and this data is then used to analyse anatomical morphology, alignment, movement and surgical instrument position (see example Fig. 1). The system will often provide a suggested plan to the surgeon, which can be over-ridden at any point. Most systems allow cuts to be verified and measured to check for any deviation from the surgical plan, however this step is not mandatory, allowing for significant deviations from the planned cuts to be made without being measured or reported in the literature.

CAS TKA has evolved to now have 2 main categories, image-based and image-free. Initial systems were either based on fluoroscopic images or an imageless CAS navigation system that required intraoperative registration of the hip and ankle center, joint surface, and various other landmarks around the knee, to create a virtual coordinate system that guides resection according to the desired alignment. Image-based systems were later developed using pre-operative $\mathrm{CT}$ and MRI to provide registration of the joint surface and overall alignment. In some instances, these systems have had additional customised cutting jigs, or 'patient specific guides' created to be used in conjunction with the CAS. More recently, accelerometer based hand-held navigation systems have been developed to assess alignment and tool position without the need for large console monitors or computer platforms. Image-based systems have recently grown in popularity with the emergence of RATKA. 


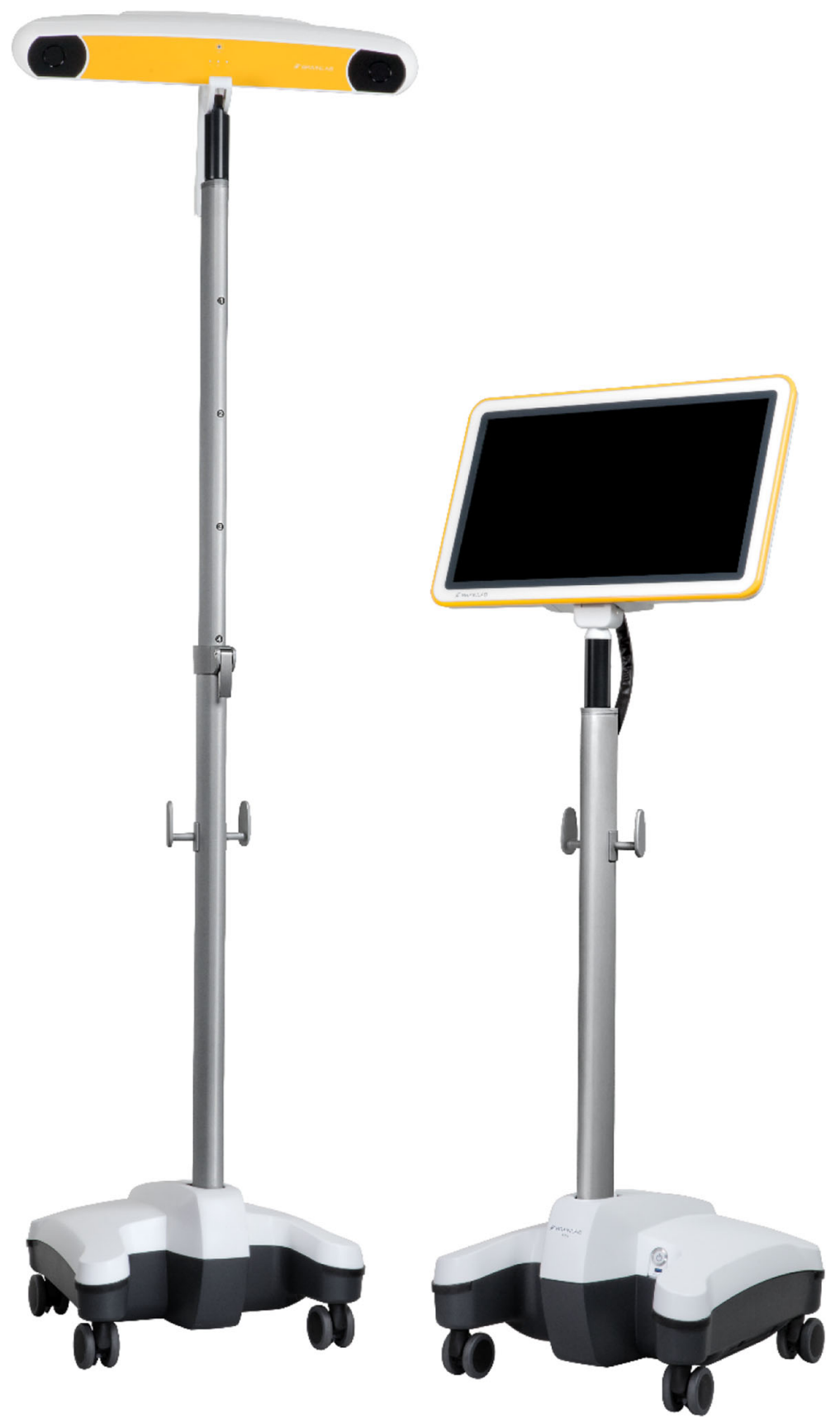

Fig. 1 BrainLab navigation unit illustrating motion capture camera and computer screen interface

Several navigations systems exist for CAS or navigated TKA. The most common are, Stryker CT-free navigation (Navigation System II; Stryker, Mahwah, New Jersey), OrthoPilot CT-free navigation (OrthoPilot version 4.2; B. Braun Aesculap, Tuttlingen, Germany), and VectorVision CT-based navigation (VectorVision version 1.6; BrainLAB, Munich, Germany) [7]. An important difference to robotic systems is that navigation units can be used with a variety of prostheses. Furthermore, differences exist between navigation systems: for example, Stryker navigation can either be an articular surface mounted (ASM) system or the precision navigation system (now called OrthoMap). In the former, the system assists with just the distal femoral and proximal tibial cuts, with no subsequent feedback regarding overall alignment or balancing. The latter also assists with these cuts, which can be verified, but also assists with implant sizing and positioning and gives feedback on alignment and balancing. Of note is that these important differences are often not controlled for in most studies assessing computer assistance with TKR. 


\section{Robotic Total knee Arthroplasty}

Two early robotic systems were developed in the 1980's for use in knee arthroplasty. The first robotic TKA was performed in 1988 using the ACROBOT (Active Constraint Robot) robotic system (Imperial College, London, United Kingdom) [8]. The company withdrew from robotics and MAKO Surgical acquired the business as part of a confidential patent infringement settlement in 2013 [9]. The CASPAR system (URS Ortho Rastatt, Germany) was also an image-guided active robot used for total hip arthroplasty and TKA. The first TKA performed was in March 2000 in Germany at the Kassel Orthopaedic clinic as part of a prospective trial after earlier being tested on saw bones and cadaveric models [10]. The CASPAR robotic system is no longer available for clinical use.

As computer-assisted surgery became more popular, several more robotic systems were developed. The ROBODOC system (Initially by Curexo Technology, Fremont, Ca, now called Think Surgical, Inc. in September, 2014) was developed and became the first robot to be used in orthopaedic surgery in the clinical setting. Initially designed for use in hip arthroplasty, a platform was later developed for use in TKA. Most of the early data regarding outcomes of robotically-assisted TKA are with the use of the ROBODOC robotic platform. In South Korea ROBODOC was first used in the clinical setting in 2001, and by 2007 more than 2000 TKA's had been performed using this system [11]. The Omnibotic robot (previously Praxim) was later approved for clinical use in 2010 and is used exclusively for TKA. Like all current robotic systems currently available for clinical use, early published data showed improved accuracy of cuts compared to conventional TKA in cadaveric models [12]. Omnibotics was acquired by CORIN group in March 2019.

The Robotic Arm Interactive Orthopedic System (RIO; MAKO Stryker, Fort Lauderdale,Florida), which utilises haptics, was more recently approved for commercial use in TKA, and has been the focus of most of the recently published literature regarding robotically-assisted TKA outcomes. Some early data has suggested that this system causes less soft tissue trauma and post-operative pain resulting in earlier discharge when compared to conventional techniques $[13,14]$. The Rosa Knee System (Zimmer Biomet, Warsaw, Indiana) is the latest robotic system approved by the FDA in January 2019. These later robotic systems have been validated in cadaveric models to show highly accurate bone cuts to achieve planned angles and resection thickness to less than $1 \mathrm{~mm}$ error [15].

Robotic TKA uses computer software to convert imaging into a virtual 3D reconstruction of the knee joint. This reconstruction can either be imageless, through anatomical landmarks gained intra-operatively such as the Navio Surgical system - Fig. 2 (Smith \& Nephew, Andover, Texas), or image-based through pre-operative radiographs such as the Rosa Knee System (Zimmer Biomet, Warsaw, Indiana), CT such as the Mako Robotic Arm Interactive Orthopaedic System (Stryker Ltd., Kalamazoo, Michigan), or a combination of pre-operative imaging and intra-operative landmarks used to morph a model such as with the Omnibotic (OMNIlife Science Inc., East Taunton, Massachusetts). Once the virtual reconstruction is created, the surgeon plans the operation and gains feedback from the model regarding the effect of changing of parameters such as implant size, position or cut orientation, on balancing and overall alignment (see Figs. 3 and 4). The surgeon then uses the robotic arm to execute this plan. Robots also usually have

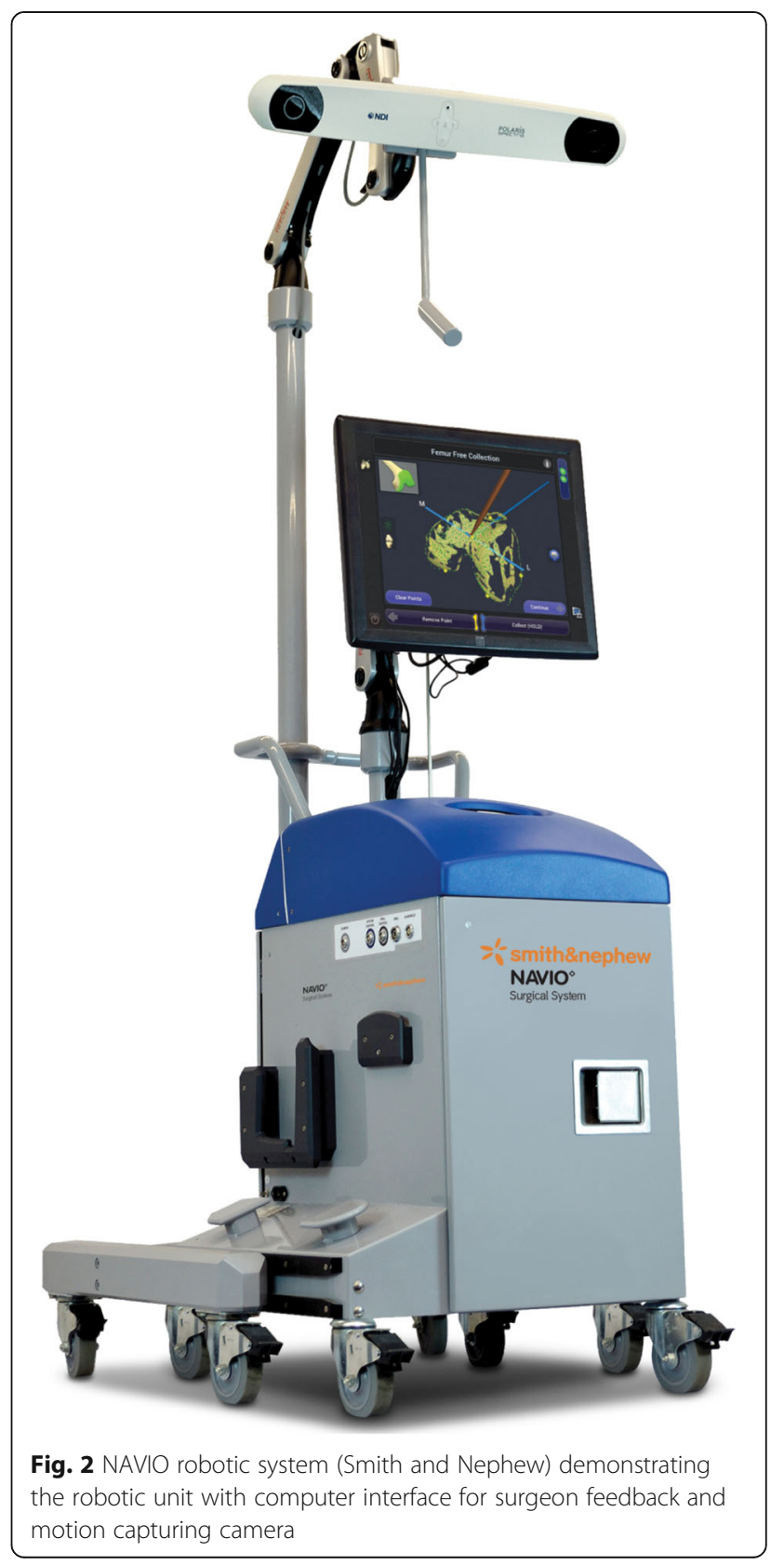




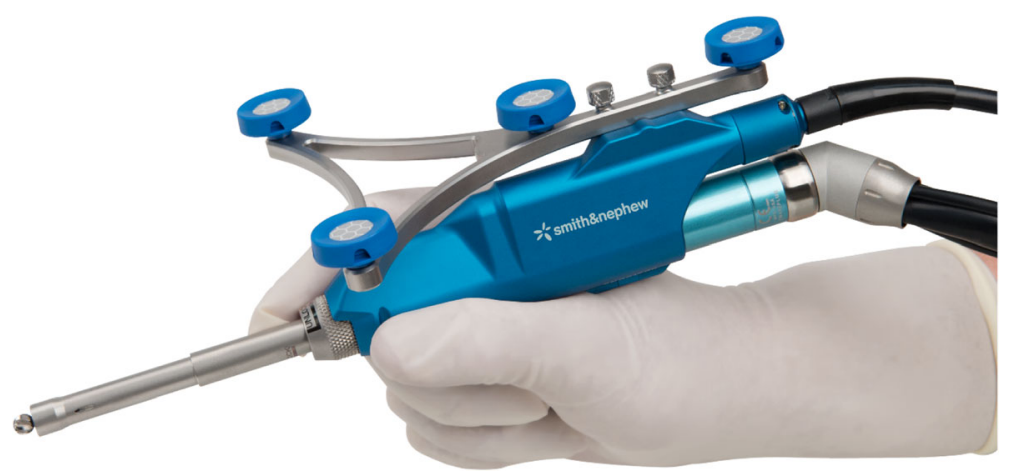

Fig. 3 Cutting burr connected to the robotic unit in image 2. The handpiece delivers the surgical plan determined by the surgeon. Whilst the surgeon still has some control over the movement of the cutting tool, some robotic systems are designed to 'cut-out' when the instrument strays from planned surgical resection margins on the plan

boundary constraint, which avoids the cutting blade or burr going beyond the planned surgical field, in order to reduce soft tissue trauma (see Fig. 5).

\section{Results}

Accuracy of CAS TKA compared to conventional TKA

Alignment and implant accuracy outcomes have received the most attention in the literature. Nearly all studies show better accuracy of CAS TKA compared to conventional methods [16-28]. Interestingly, the benefit of navigation appears most consistent in the coronal plane. Fewer studies have reported accuracy of axial alignment, with just two studies showing improved rotational alignment for CAS TKA compared to conventional TKA [23, 29]. One possible explanation for this observation is that in some instances navigation may only be used for accuracy of coronal cuts, and sagittal and axial alignment in some systems are either not measured, or surgeons may prefer to use manual techniques for this part of the procedure, and this is not captured in

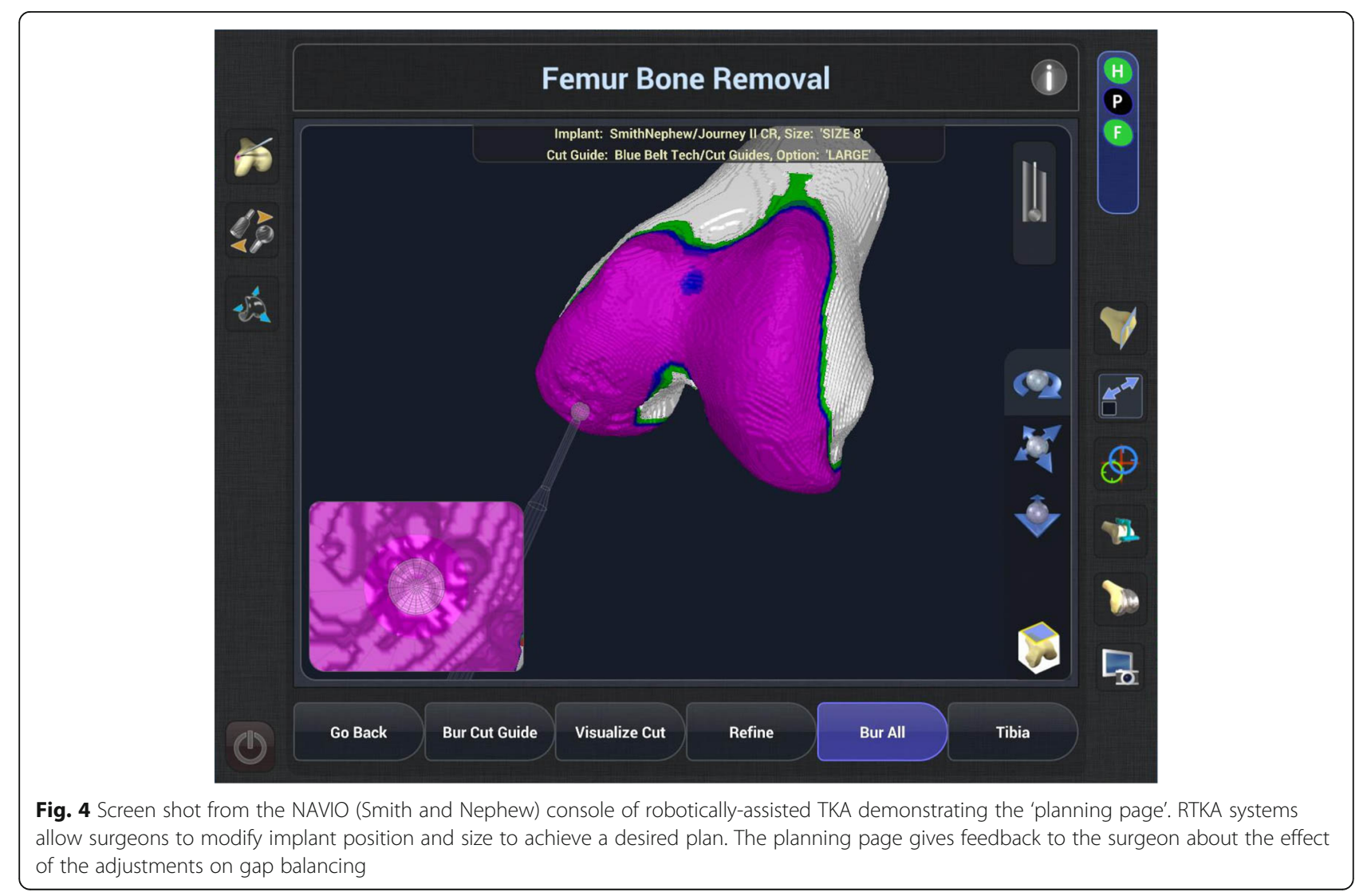




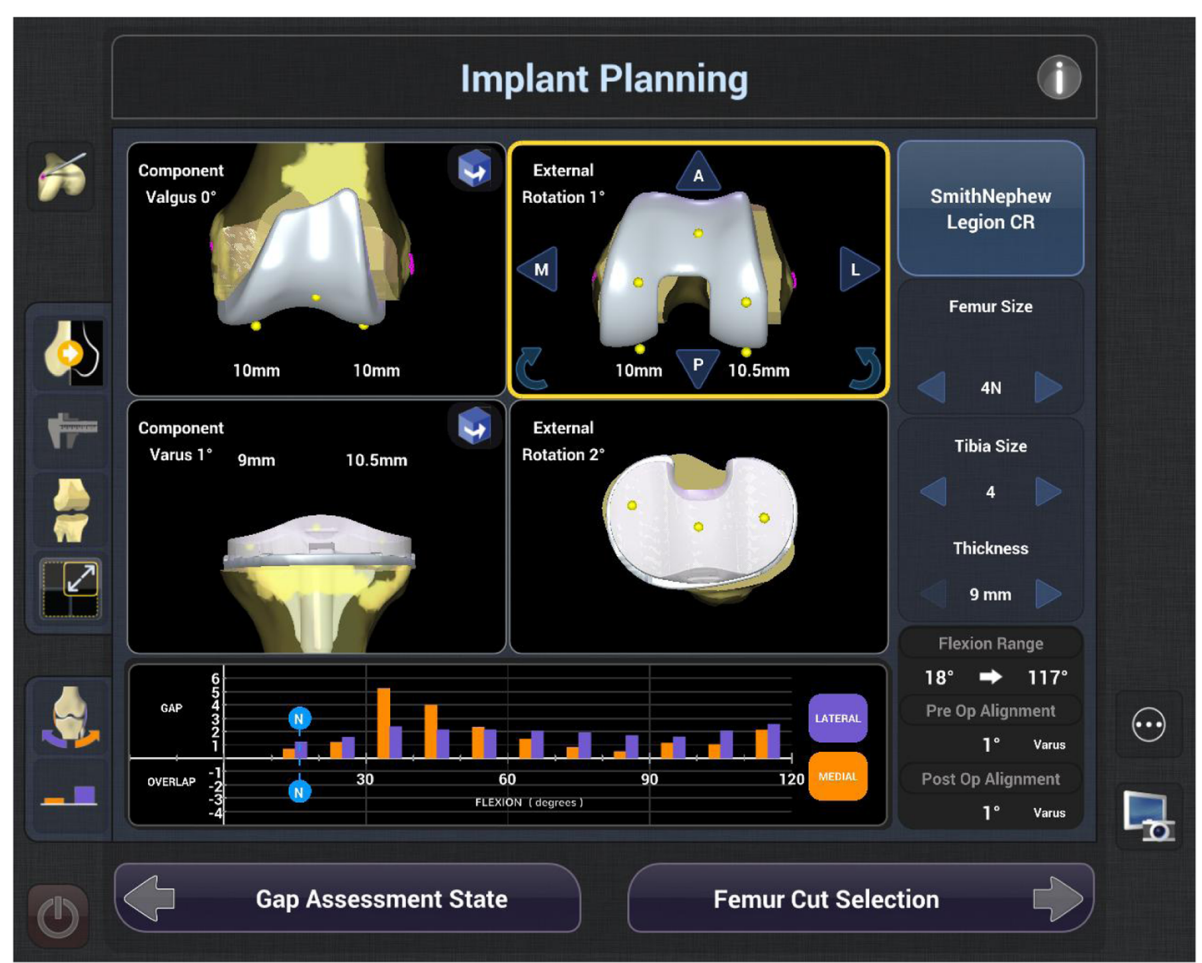

Fig. 5 Screen shot from the NAVIO (Smith and Nephew) console of robotically-assisted TKA demonstrating planned bone resection (purple). Robotic-systems allow implant position and sizing to be 'virtually' trialled giving the surgeon feedback on the effect on gap balancing, notching, prosthesis overhang etc

the literature. In addition, for the more commonly used image -free systems, rotational landmarks require surgeon identification without any assistance from the computer, and landmarks such as epicondyles are less reproducible than simpler landmarks such as centre of femur and tibia.

Only one study comparing implant accuracy between RATKA and CAS TKA techniques has been published [30]. In a retrospective study of 81 matched patients, RATKA was 0.5 degrees closer to planned coronal alignment than CAS TKA when comparing the PRAXIM robot to a Stryker navigation system. In this study $37 \%$ of the femoral cuts were within a half degree of the planned cut angle, $63 \%$ of axial rotations were within a half degree, and $50 \%$ of the tibia slope cuts were within a half degree of the planned value.

\section{Patient reported outcomes for CAS TKA compared to conventional TKA}

PROMs of CAS TKA compared to conventional TKA are summarised in Table 1. PROM data was available from 19 studies totalling 1978 TKA. 12 of the studies reported higher PROM scores compared to conventional TKA although this often did not reach statistical or clinical significance. Follow-up periods range from 2 to 15 years. None of the studies found a statistically significant difference between CAS TKA and conventional TKA PROMs at any time point, however there is a weak but consistent benefit for navigation over conventional TKA at short, medium and long-term follow-up.

\section{Survivorship outcomes for CAS versus conventional TKA}

Results are summarised in Table 2. US data [52] shows computer navigation increased in use from $1.2 \%$ in 2005 to $6.3 \%$ in 2014and 24,084 (0.4\%) use robotic assistance for TKA. The proportion of technology-assisted TKAs has increased from $1.2 \%$ in 2005 to $7.0 \%$ in 2014. Computer navigation increased in use from $1.2 \%$ in 2005 to $6.3 \%$ in 2014 . In Australia in 2002 2.4\% (526) of all TKA were performed using CAS, and by 2018 this had increased to 33\% (18,529) of all TKA [1]. In 2014, data on CAS TKA included 10 different navigation systems, but Brainlab (48.6\%) and Stryker (31.8\%) made up the majority of cases reported to the Australian registry. No survivorship data comparing robotically-assisted to CAS TKA has been published to date, however short-term data from the AOA ANJRR on robotic UKR has demonstrated reduced revision rates at 3 years compared to non-robotic UKR (2.8\% versus $4.6 \%)$ [1].

The Australian National Joint Registry 2019 Annual report on 132,211 TKA performed using CAS showed a small benefit overall for revision rates compared to conventional TKA. When analysed for patients under 65 


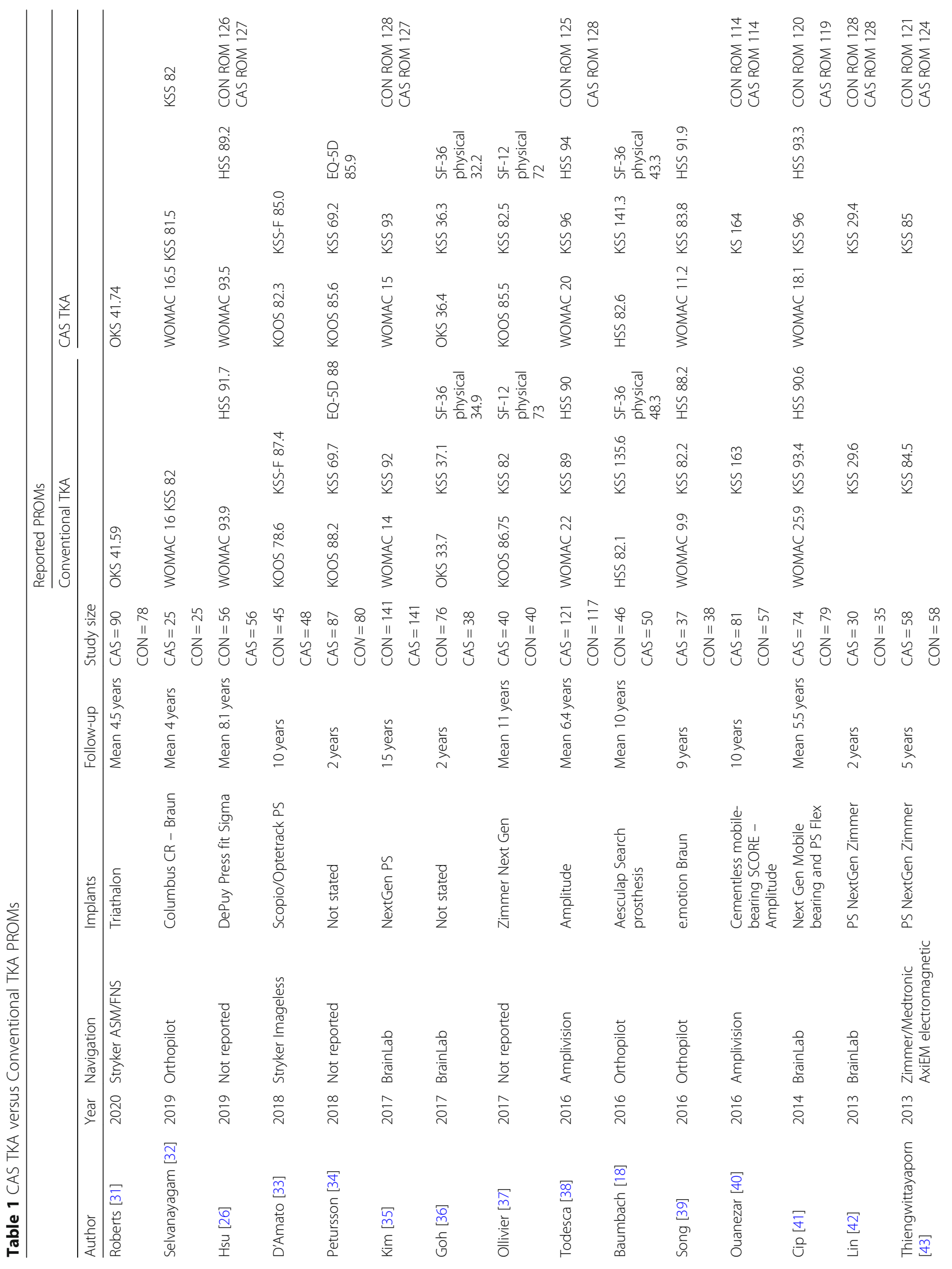




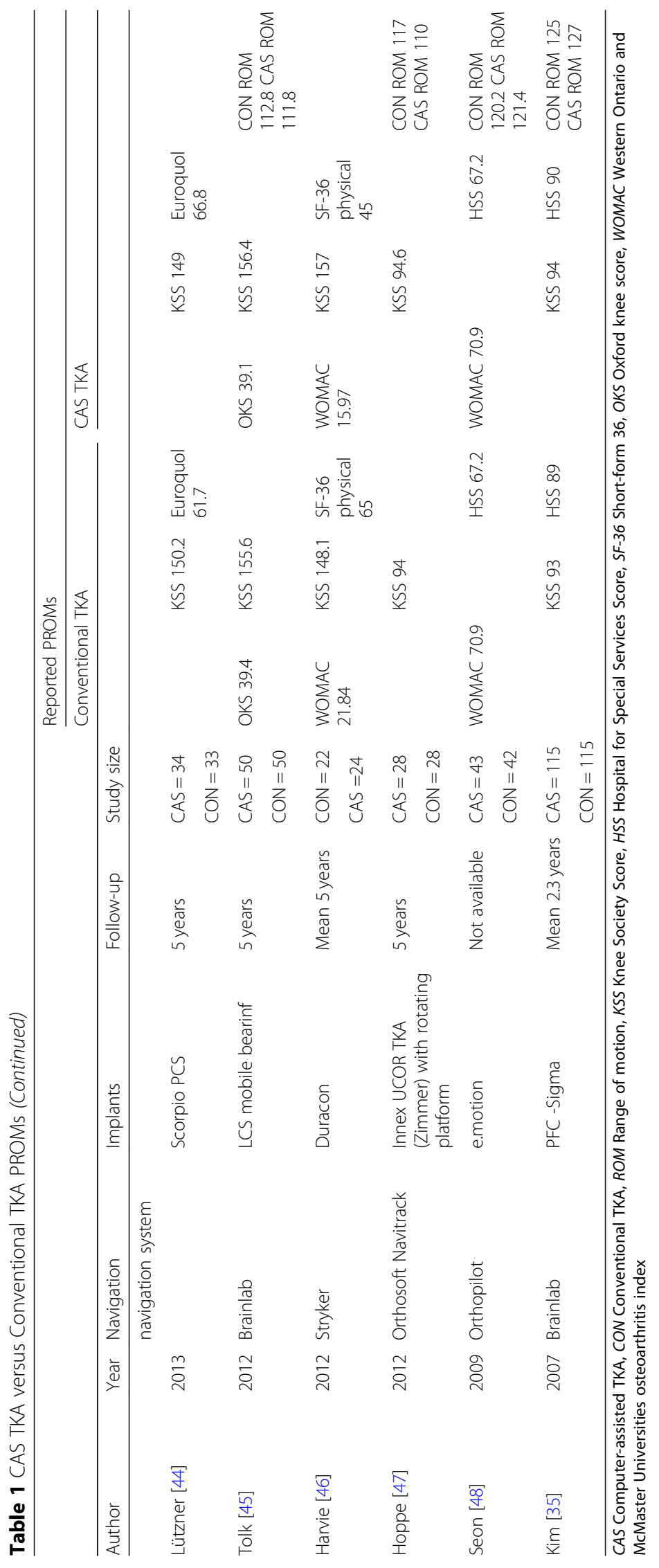


Table 2 CAS TKA versus Conventional TKA Survivorship

\begin{tabular}{|c|c|c|c|c|c|c|}
\hline \multirow[b]{2}{*}{ Author } & \multirow[b]{2}{*}{ Year } & \multirow[b]{2}{*}{ Navigation } & \multirow[b]{2}{*}{ Implants } & \multirow[b]{2}{*}{$\begin{array}{l}\text { Follow- } \\
\text { up }\end{array}$} & \multicolumn{2}{|l|}{ Survivorship } \\
\hline & & & & & CAS TKA & CON TKA \\
\hline \multirow[t]{2}{*}{ Roberts [31] } & \multirow[t]{2}{*}{2020} & \multirow{2}{*}{$\begin{array}{l}\text { Stryker ANS/ } \\
\text { ASM }\end{array}$} & \multirow[t]{2}{*}{ Triathalon } & \multirow[t]{2}{*}{10 years } & $95.6 \%(n=10,404)$ & $95.1 \%(n=9501)$ \\
\hline & & & & & $<65$ years $95.6 \%$ & $<65$ years $95.1 \%$ \\
\hline $\begin{array}{l}\text { Selvanayagam } \\
{[32]}\end{array}$ & 2019 & Orthopilot & Columbus CR - Braun & 4 years & $100 \%(n=40)$ & $100 \%(n=40)$ \\
\hline D'Amato [33] & 2019 & Stryker & Scorpio/Optitrak & 10 years & $96.2 \%(n=48)$ & $94.3 \%(n=45)$ \\
\hline Ollivier [37] & 2017 & Unknown & NextGen & 13 years & $97 \%(n=40)$ & $97 \%(n=40)$ \\
\hline Todesca [38] & 2017 & Amplivision & Amplitude & 7 years & $100 \%(n=117)$ & $100 \%(n=121)$ \\
\hline Kim [49] & 2017 & BrainLab & NextGen PS & 15 years & $99 \%(n=141)$ & $99 \%(n=141)$ \\
\hline \multirow[t]{2}{*}{ Dyrhovden [50] } & \multirow[t]{2}{*}{2016} & \multirow[t]{2}{*}{ Misc. $^{a}$} & \multirow[t]{2}{*}{ Misc. ${ }^{b}$} & \multirow[t]{2}{*}{8 years } & $94.8 \%(n=354)$ & $94.9 \%(n=2836)$ \\
\hline & & & & & $\begin{array}{l}<65 \text { years } 93.6 \%(n= \\
126)\end{array}$ & $\begin{array}{l}<65 \text { years } 92.4 \%(n= \\
955)\end{array}$ \\
\hline Baumbach [18] & 2016 & Not stated & Aesculap Search prosthesis & 10 years & $98 \%(n=50)$ & $87 \%(n=46)$ \\
\hline Ouanezar [40] & 2016 & Amplivision & $\begin{array}{l}\text { Cementless mobile-bearing SCORE - } \\
\text { Amplitude }\end{array}$ & 10 years & $91 \%(n=87)$ & $86 \%(n=51)$ \\
\hline Song [39] & 2016 & Orthopilot & e.motion Braun & 9 years & $100 \%(n=37)$ & $95.3 \%(n=38)$ \\
\hline \multirow[t]{2}{*}{ De Steiger [51] } & \multirow[t]{2}{*}{2015} & \multirow[t]{2}{*}{ Multiple } & \multirow[t]{2}{*}{ Multiple } & \multirow[t]{2}{*}{9 years } & $95.4 \%$ & $94.8 \%$ \\
\hline & & & & & $<65$ years $93.7 \%$ & $<65$ years $92.2 \%$ \\
\hline Cip [41] & 2014 & BrainLab & Next Gen Mobile bearing and PS Flex & 5.5 years & $98.9 \%(n=74)$ & $95.4 \%(n=79)$ \\
\hline
\end{tabular}

a Prosthesis brands (AGC, Duracon, e.motion, LCS complete, and Profix)

${ }^{b}$ Navigation systems (Brainlab, Orthopilot, and Stryker)

CAS Computer-assisted TKA, CON Conventional TKA, KSS Knee Society Score, HSS Hospital for Special Services Score, SF-36 Short-form 36, OKS Oxford knee score, WOMAC Western Ontario and McMaster Universities osteoarthritis index

this benefit is more pronounced. Comparing CAS TKA to conventional TKA, revision rate at 15 years was $7.1 \%$ versus $7.4 \%$. In patient over 65 , revision rate was $5.4 \%$ for CAS TKA versus $5.2 \%$ for conventional TKA at 15 year follow-up. For patients under 65 for conventional TKA, revision rate was $9.7 \%$ versus $11.2 \%$ respectively. De Steiger [51] first reported this observation in 2015, noting that the rate of aseptic loosening was higher in the conventional TKA group. More recent data shows this trend continuing and becoming more pronounced in the under 65 group with time.

Data from 23,884 primary total knee replacements without patella resurfacing, reported to the Norwegian Arthroplasty Register during the years 2005-2014, were evaluated by Dyrhovden et al. [50]. Analysis of the 5 most used prosthesis brands (AGC, Duracon, e.motion, LCS complete, and Profix) and the 3 most frequently used navigation systems (Brainlab, Orthopilot, and Stryker) were reported. At 8 years followup, the revision rate was $5.1 \%$ in the CAS group and $4.2 \%$ in the conventional group. For people $<65$, revision rate at 8 years was $6.4 \%$ for CAS versus $7.3 \%$ for conventional TKA.

Data from the New Zealand Joint Registry [31] compared outcomes in nearly 20,000 TKA performed by high volume arthroplasty surgeons ( $>50$ per annum) with mean 4.5 years follow-up. CAS was used in 10,404 TKA and conventional instrumentation was used in 8817. Data in this report was with a single CAS system and implant type (Triathlon TKA; Stryker Orthopaedics) using Stryker's Full Navigation System (FNS) and its abbreviated variant, the Articular Surface Mounted (ASM) Navigation System. In patients $<65$ years of age, the 5 -year cumulative revision rate was $3.0 \%$ for the CAS group and $2.9 \%$ for the conventional TKA. At 10 years, the cumulative revision rates for patients $<65$ years of age was $4.4 \%$ for the CAS group and $4.9 \%$ for the conventional TKA group and this difference was not deemed to reach statistical significance In comparison, data from the Australian registry at 10 year follow-up showed a revision rates in patients $<65$ of $6.9 \%$ for CAS and $7.8 \%$ for conventional, showing a higher revision rate than was seen in the NZ data.

In a smaller study of 135 knees with 10 year follow-up, there was a trend towards a higher rate of revision in non-navigated TKA using an uncemented prosthesis. This was explained by increased rates of secondary patella resurfacing being required in the conventional group [40]. Kim et al. [49] demonstrated 98\% survivorship in both conventional and CAS TKA in patients under $65 \%$ with minimum 14 years follow-up.

Whilst some of the larger registries report improved survival with the use of computer navigation for TKA, this finding is not universal across all registries and all 
studies examining this. It would certainly appear that the improved alignment achieved with CAS may have a beneficial effect on reducing the revision rate from wear and loosening, particularly in younger, more active patients, but ongoing analysis is clearly required before more definitive conclusions can be drawn.

\section{Accuracy of robotic TKA compared to conventional TKA}

Data from 7 studies comparing implant accuracy of RATKA to conventional technique (Table 3) was available. RATKA has less outliers than conventional TKA. Whilst the trend towards improved accuracy is consistent amongst all studies, the strength of the difference between the two groups is heterogenous. Song et al. [57] reported no radiographic outliers in the coronal or sagittal alignment of RATKA, versus $20 \%$ coronal and up to $50 \%$ sagittal outlier inaccuracy of conventional techniques in a series comparing 100 TKA. Jeon et al. [55] also found improved implant accuracy of RATKA over conventional methods, but with a smaller difference (10.7\% versus $16.5 \%$ coronal outliers for RATKA versus conventional). Interestingly, RATKA appears to improve implant accuracy by a similar difference in the coronal and sagittal planes compared to conventional TKA. There is currently insufficient comparative data regarding implant axial accuracy between these two groups.

\section{Patient reported outcomes for robotic-assisted TKA compared to conventional TKA}

Results are summarised in Table 4. As expected, data on RATKA is relatively small in numbers and shorter in follow-up when compared with either CAS or manual instrumented techniques. Ten-studies were found comparing PROMs between robotic and navigated TKA. Results show a small benefit to RATKA without reaching statistical significance in any of the studies reviewed. Eight of the ten compare the ROBODOC robot to conventional TKA, and the remaining 2 compare the MAKO robot. Interestingly, one study [59] found a $20 \%$ higher patient satisfaction rate in patients undergoing RATKA versus conventional despite no statistically significant difference in ROM, WOMAC or knee scores.

\section{Robotic-assisted TKA current trends and survivorship compared to conventional TKA}

Limited long-term data is available that compares robotically-assisted to conventional TKA, and owing to the short-term follow-up national joint registries have not yet made reports on robotically-assisted TKA publicly available. Results are summarised in Table 5. Only one study demonstrated improved implant survival comparing RATKA to conventional TKA [53], and no study demonstrated worse results with RATKA.

\section{Discussion}

The most important finding from our review was that CAS TKA improves accuracy and consistency of implant position, and appears to provide a small improvement in PROMs and implant survival compared to conventional TKA. RATKA likewise improves implant accuracy compared to conventional techniques and early results suggest a similar small benefit in PROMs compared to conventional TKA. A strengthening trend is emerging showing CAS TKA has greatest benefit to implant survival in

Table 3 Studies Comparing Radiographic Outliers in RATKA Versus Conventional TKA

\begin{tabular}{|c|c|c|c|c|c|c|c|c|}
\hline \multirow[b]{2}{*}{ Author } & \multirow[b]{2}{*}{ Year } & \multirow[b]{2}{*}{ Robot } & \multirow[b]{2}{*}{ Number } & \multirow[b]{2}{*}{ C-Mechanical \% ${ }^{a}$} & \multicolumn{4}{|c|}{ Percentage of Radiographic Outliers } \\
\hline & & & & & C-Femur & C-Tibia & S-Femur & S-Tibia \\
\hline \multirow[t]{2}{*}{ Yang [53] } & 2017 & ROBODOC Vs Next Gen & 113 & $R-8.7$ & $R-5.8$ & $R-1.5$ & $R-14$ & $R-8.7$ \\
\hline & & & & $C-33$ & $C-31$ & $C-10.3$ & $C-59$ & $C-41$ \\
\hline \multirow[t]{2}{*}{ Kim [54] } & 2019 & ROBODOC Vs Duracon & 1348 & $R-14$ & $R-11$ & $R-11$ & $R-12$ & $R-11$ \\
\hline & & & & $C-26$ & $C-21$ & $C-20$ & $C-21$ & $C-20$ \\
\hline \multirow[t]{2}{*}{ Jeon $[55]$} & 2019 & ROBODOC NextGen (Robotic) & 163 & $R-10.7$ & $R-8.3$ & $R-11.9$ & $R-3.6$ & $R-20.2$ \\
\hline & & Triathalon (conventional) & & $C-16.5$ & $C-11.4$ & $C-11.4$ & $C-6.3$ & $C-15.2$ \\
\hline \multirow[t]{2}{*}{ Cho $[56]$} & 2018 & ROBODOC & 390 & $R-10.6$ & $R-8$ & $\mathrm{R}-7.1$ & $R-35.9$ & $R-5.3$ \\
\hline & & & & $C-26.4$ & $C-15$ & $C-7.9$ & $C-32.9$ & $C-32.1$ \\
\hline \multirow[t]{2}{*}{ Song [57] } & 2013 & ROBODOC vs NextGen & 100 & $\mathrm{R}-0$ & $\mathrm{R}-0$ & $\mathrm{R}-0$ & $\mathrm{R}-0$ & $R-2$ \\
\hline & & & & $C-24$ & $C-4$ & $C-6$ & $C-0$ & $C-6$ \\
\hline \multirow[t]{2}{*}{ Song [58] } & 2011 & ROBODOC vs NextGen & 60 & $R-0$ & $R-0$ & $R-0$ & $R-0$ & $R-6.7$ \\
\hline & & & & $C-23.3$ & $C-26.7$ & $C-0$ & $C-10$ & $C-50$ \\
\hline \multirow[t]{2}{*}{ Siebert [10] } & 2002 & CASPAR Vs NextGen & 120 & R- 98 & - & - & - & - \\
\hline & & & & $C-65$ & & & & \\
\hline
\end{tabular}


Table 4 Robotic TKA versus Conventional TKA PROMs

\begin{tabular}{|c|c|c|c|c|c|c|c|}
\hline \multirow[b]{2}{*}{ Author } & \multirow[b]{2}{*}{ Year } & \multirow[b]{2}{*}{ Robot } & \multirow[b]{2}{*}{$\begin{array}{l}\text { Follow- } \\
\text { up }\end{array}$} & \multirow[b]{2}{*}{$\begin{array}{l}\text { Study } \\
\text { size }\end{array}$} & \multicolumn{2}{|l|}{ Reported PROMs } & \multirow{2}{*}{$\begin{array}{l}\text { RTKA } \\
\text { ROM }\end{array}$} \\
\hline & & & & & Conventional TKA & & \\
\hline \multirow[t]{2}{*}{ Smith [59] } & \multirow[t]{2}{*}{2019} & \multirow[t]{2}{*}{ MAKO vs Triathalon } & \multirow[t]{2}{*}{1 year } & $\begin{array}{l}\text { RTKA } \\
120\end{array}$ & $\begin{array}{l}\text { Satisfied/very satisfied } \\
\text { (Likert) } 82 \%\end{array}$ & $\begin{array}{l}\text { Satisfied/very satisfied } \\
\text { (Likert) } 94 \%\end{array}$ & RTKA 0-119 \\
\hline & & & & $\begin{array}{l}\text { CON } \\
113\end{array}$ & KSS Function - 73 & KSS Function - 80 & CON 1-116 \\
\hline \multirow[t]{2}{*}{ Kim [54] } & \multirow[t]{2}{*}{2019} & \multirow[t]{2}{*}{ ROBODOC Vs PS Duracon } & \multirow[t]{2}{*}{13 years } & $\begin{array}{l}\text { RTKA } \\
674\end{array}$ & KSS-KS 93 & KSS-KS 92 & RTKA 125 \\
\hline & & & & $\begin{array}{l}\text { CON } \\
674\end{array}$ & WOMAC 18 & WOMAC 19 & CON 128 \\
\hline \multirow[t]{3}{*}{ Jeon [55] } & \multirow[t]{3}{*}{2019} & \multirow{3}{*}{$\begin{array}{l}\text { Robodoc (NextGen) Vs } \\
\text { Triathalon }\end{array}$} & \multirow[t]{3}{*}{10 years } & RTKA 84 & KSS 91.9 & KSS 89.7 & RTKA 137.2 \\
\hline & & & & CON 79 & KSS Function 85.4 & KSS Function 89.5 & \multirow[t]{2}{*}{ CON 134.5} \\
\hline & & & & & SF-36 (physical) 47.2 & SF-36 (physical) 47.5 & \\
\hline \multirow[t]{5}{*}{ Cho [56] } & \multirow[t]{5}{*}{2018} & \multirow[t]{5}{*}{ ROBODOC Vs NextGen } & \multirow[t]{5}{*}{10 years } & $\begin{array}{l}\text { RTKA } \\
160\end{array}$ & HSS 86.7 & HSS 88.5 & \multirow[t]{5}{*}{$\begin{array}{l}\text { RTKA130.7 CON } \\
130.0\end{array}$} \\
\hline & & & & \multirow{4}{*}{$\begin{array}{l}\text { CON } \\
230\end{array}$} & KSS Pain 45.8 & KSS Pain 45.3 & \\
\hline & & & & & KSS Function 88.4 & KSS Function 87.8 & \\
\hline & & & & & WOMAC 13.0 & WOMAC 10.1 & \\
\hline & & & & & SF-36 P 47.6 & SF-36 P 48.3 & \\
\hline \multirow[t]{3}{*}{ Yang [53] } & \multirow[t]{3}{*}{2017} & \multirow[t]{3}{*}{ ROBODOC vs NextGen } & \multirow[t]{3}{*}{10 years } & RTKA 71 & HSS 88.7 & HSS 87.2 & RTKA 132.6 CON \\
\hline & & & & CON 42 & WOMAC 11.5 & WOMAC 7.6 & \\
\hline & & & & & VAS 1.1 & VAS 1.2 & \\
\hline Marchand & 2017 & MAKO Vs CR Triathalon & & RTKA 20 & Pain score $5 / 10$ & Pain score $3 / 10$ & \\
\hline & & & & CON 20 & WOMAC 14 & WOMAC 7 & \\
\hline Liow [61] & 2016 & ROBODOC vs NextGen & 2 years & RTKA 31 & OKS 17.7 & OKS 18.3 & RTKA 1.5-118.3 \\
\hline & & & & CON 29 & KSS-F 73.9 & KSS - F 77 & CON 1.7-125.2 \\
\hline & & & & & KSS-KS 87.9 & KSS - KS 81.8 & \\
\hline & & & & & SF-36 Physical 66.9 & SF-36 Physical 79.5 & \\
\hline & & & & & Satisfied (\%) 89.7 & Satisfied (\%) 93.5 & \\
\hline Song [57] & 2013 & ROBODOC & 5.4 years & RTKA 50 & WOMAC 30 & WOMAC 28.9 & RTKA 128 \\
\hline & & $v_{s}$ & & CON 50 & HSS 94.7 & HSS 95.7 & CON 129 \\
\hline Song [58] & 2011 & ROBODOC Vs CR NextGen & 1.4 years & RTKA 30 & WOMAC 13 & WOMAC 11 & RTKA 129 \\
\hline & & & & CON 30 & HSS 94.7 & HSS 95.2 & CON 129 \\
\hline Park [11] & 2007 & ROBODOC Vs Zimmer LPS & 3.75 & RTKA 30 & KSS 90.4 & KSS 91.6 & RTKA 122 \\
\hline & & & $y \in$ & CON 32 & $\begin{array}{l}\text { Knee Functional Score - } \\
88.5\end{array}$ & $\begin{array}{l}\text { Knee Functional Score - } \\
87.9\end{array}$ & CON 118 \\
\hline
\end{tabular}

CAS Computer-assisted TKA, RTKA Robotic TKA, KSS Knee Society Score, HSS Hospital for Special Services Score, SF-36 Short-form 36, OKS Oxford knee score, WOMAC Western Ontario and MCMaster Universities osteoarthritis index, VAS Visual Analogue Scale

Table 5 Robotic TKA versus Conventional TKA Survivorship

\begin{tabular}{lllllll}
\hline & & & & & \multicolumn{2}{l}{ Survivorship } \\
\cline { 6 - 7 } Author & Year & Navigation & Implants & Follow-up & RATKA & CON TKA \\
\hline Kim [54] & 2020 & ROBODOC & PS Duracon & 15 years & $100 \%(n=724) 84$ & $100 \%(n=724) 74$ \\
Jeon [55] & 2019 & ROBODOC & NextGen (Robotic) & 10 years & $98.8 \%(n=84)$ & $97.5 \%(n=79)$ \\
& & & Triathalon (conventional) & & & \\
Cho [56] & 2019 & ROBODOC & NextGen & 13.5 years & $98.8 \%(n=160)$ & $98.5 \%(n=230)$ \\
Yang [53] & 2017 & ROBODOC & NextGen & 10 years & $97.1 \%(n=71)$ & $92.3 \%(n=42)$ \\
\hline
\end{tabular}


people under 65. RATKA survival analysis data is more limited and early results do not allow strong conclusions, however early trends are similar to CAS TKA.

The benefit of improved alignment accuracy appears slightly greater in the coronal plane compared to the sagittal plane. This is consistent with a recent meta-analysis showed improved accuracy when comparing CAS to conventional TKA [7]. In this study pooled results showed femoral component alignment was satisfactory in $95 \%$ of cases versus $84 \%$ of cases in the conventional group. Similarly with the tibial components, malalignment was present in $21 \%$ of conventional TKA versus 5\% of CAS TKA. Fewer studies have reported accuracy and consistency with rotational alignment, but both CAS TKA and RATKA appear to be more accurate in the axial plane as well compared to RATKA [23, 29]. This is consistent with a previous metanalysis that found CAS TKA had fewer outliers than conventional TKA for rotational accuracy of implant position [62]. We did not identify any studies comparing axial accuracy of implant positioning of robotic to conventional TKA, although it would seem intuitive that image-based systems may allow more accurate identification of rotational landmarks, and this should be a focus of future research.

This clear difference in radiographic parameters is not consistently reflected in PROMs. Nonetheless, there does appear to be a small advantage to PROMs when using CAS over conventional TKA. These results are consistent with a recent meta-analysis of level 1 and 2 studies comparing CAS to conventional TKA [63], although it is worth noting that despite often finding significant differences, the minimal clinically important difference is often not reached [64]. It is not well established why improvements in accuracy do not lead to larger differences in PROMs, but there are several possible explanations for this. The majority of studies fail to measure rotational alignment accuracy, and this can certainly influence outcomes. It is also possible that small differences in coronal and sagittal alignment may not have a clinically meaningful impact on outcomes, or that current measurement tools are not sensitive to measure the differences in outcome that patients may otherwise appreciate. Other variables not controlled, particularly more recently, are those introduced by different alignment philosophies. Similar results were found when comparing PROMs for RATKA to conventional TKA, and whilst there was a trend towards improved outcomes for RATKA, no study found a statistically significant difference and these findings are similar to a recent meta-analysis by Ren et al. [65]. PROMs for RATKA are comparatively smaller in number and have shorter follow-up than navigated TKA, and it is therefore it is difficult at this point to draw any strong conclusions from the data available.

Survivorship shows promising signs for CAS TKA compared to conventional TKA, particularly in people under the age of 65 . In our review, no study showed conventional TKA being superior to CAS TKA in survival analysis, and $5[18,39-41,51]$ of 11 studies reported improved survival with CAS. It is plausible that malaligned implants causes eccentric polyethylene wear, with increased risk of aseptic loosening. This is supported by findings by Baumbach et al. who found at 10 year follow up an aseptic loosening rate of $17 \%$ of conventional and $9.8 \%$ of the navigated TKAs, with $58 \%$ versus $78 \%$ being within $+/-3$ degrees of a neutral mechanical alignment [18]. However, Roberts et al. [31] reported New Zealand joint registry data and found no significant difference in survival for over or under 65 year old patients, when comparing CAS to conventional TKA, in contrast to Australian joint registry findings. It is important to note however, that this analysis only included outcomes of high-volume surgeons using a single prosthesis and navigation system (Stryker; Triathalon). Differences in registry results may also in part be due to prosthesis choice, such as the LCS which was reported to have inferior results with CAS in the short-term on the Norwegian registry [50] and the inability to account for other potentially important variables including surgeon volume and experience, and the type of navigation system used.

RTKA represents an extension of CAS systems, offering more comprehensive planning, additional feedback, and a precise delivery tool. Relatively limited data regarding survival analysis of RATKA to conventional TKA is available, but results show similar trends to that of CAS TKA [53-56]. Kim et al. [54] reported the longest follow-up data between conventional and RTA, and reported a remarkable $100 \%$ implant survival at 15 year follow-up for both conventional and RATKA groups. Yang et al. [53] reported 10 year outcomes of 113 TKA performed using the ROBODOC platform in comparison to conventional TKA. Cumulative survival in the robotic group and the conventional group was $97.1 \%$ and $92.3 \%$, respectively, at 10 years. Both groups had 2 knees revised for infection. It should be noted that comparative studies to date have all used one robotic system, ROBODOC, and it unclear if other more contemporary robotic TKA systems will have different results. RATKA provides a more comprehensive surgical planning tool allowing for more precise implant positioning and sizing. It also provides virtual gap balancing, something that only some computer navigation systems provide. It is also important to note that most robotic systems must be used with a specific prosthesis, making this a potentially valuable marketing tool for the orthopaedic industry. Robotic systems also capture large volumes of data, which could potentially be used by industry to record and analyse surgeon preferences or techniques for future product development, and ownership and use of this data remains unclear. 
Critics of CAS and RATKA site complication risk without evidence of clear benefit as reason for non-use. Pin secured navigation systems have in some studies been associated with tibial and femoral diaphyseal fractures in $1 \%$ of cases $[66,67]$ and a superficial wound infection rate of $1-5 \%[68,69]$. This has not been our experience. In the case of the senior author, over 4000 navigated TKA have been performed using pin fixation for navigation without sustaining a pin site fracture, and this complication can usually be avoided by not placing pins trans-cortically. Liow reported $16 \%$ vs $6.9 \%$ complication rate in RATKA vs conventional TKA, but operation length of time was similar. In this study, 3 out of 31 patients had RATKA aborted. However, Siebert et al. published the earliest series of RATKA using the CASP AR robot compared to the conventional technique with few complications in the RATKA group and a quick learning curve [10]. Another concern regarding CSA and RATKA is perceived increased length of operation time [24], and recent registry study from New Zealand [31] showed CAS TKA averaged $10 \mathrm{~min}$ longer operating time compared to conventional techniques. It is our experience that once surgeons become familiar with these techniques, additional operating time is negligible. There are of course additional practical considerations often not addressed in the literature. Surgical time is reported, but not set-up time which can be substantial in some cases. The requirement of additional industry support personnel to be present increases traffic in and out of theatre which may increase risk of periprosthetic joint infections, and robotic units require space in the operating room, which may already be overcrowded.

\section{Conclusion}

Navigation in TKA was introduced with the intention of improving implant alignment with the hope that this would lead to improvement in PROMs and implant survival. Early data showed clear improvement in alignment, and early clinical outcomes showed promising results, with longer-term data and medium-term survival analysis recently emerging showing small benefits over conventional TKA. RATKA represents another phase of development, offering more comprehensive planning, additional feedback and a delivery tool. Early results show similar trends to that of CAS TKA with longerterm data still to come. These emerging technologies are tools available to surgeons, and surgeons need to be familiar with what is available, gain the appropriate experience necessary to use a system effectively, and decide which techniques provide them and their patients with the optimum outcomes. Further research is always necessary, and widespread adoption of new technology should always be evidence based.

\section{Supplementary information}

Supplementary information accompanies this paper at https://doi.org/10. 1186/s40634-020-00278-y.

Additional file 1: Table 3. Radiographic Accuracy of CAS TKA versus Conventional TKA

\section{Acknowledgements}

The authors would like to thanks Smith and Nephew for allowing images to be included in this manuscript.

\section{Authors' contributions}

Both authors contributed to the article. The first author is the corresponding author. The author(s) read and approved the final manuscript.

\section{Funding}

None to disclose.

\section{Availability of data and materials}

All data and materials are contained in the manuscript or supplementary materials section.

Ethics approval and consent to participate

Not required.

\section{Consent for publication}

Not required.

\section{Competing interests}

None to disclose.

\section{Author details}

${ }^{1}$ Royal North Shore Hospital, St Leonards, Australia. ${ }^{2}$ Sydney Orthopaedic Research Institute, Chatswood, Australia. ${ }^{3}$ University of Sydney, Sydney, Australia.

Received: 11 June 2020 Accepted: 17 August 2020

Published online: 24 September 2020

\section{References}

1. Australian Orthopaedic Association (2019) 20th Australian Orthopaedic Association National Joint Replacement Registry Annual Report. Australian Orthopaedic Association

2. Gilmour A, MacLean AD, Rowe PJ, Banger MS, Donnelly I, Jones BG et al (2018) Robotic-arm-assisted vs conventional Unicompartmental knee Arthroplasty. The 2-year clinical outcomes of a randomized controlled trial. J Arthroplast 33:S109-S115

3. Naziri Q, Mixa PJ, Murray DP, Abraham R, Zikria BA, Sastry A et al (2018) Robotic-assisted and computer-navigated Unicompartmental knee Arthroplasties: a systematic review. Surg Technol Int 32:271-278

4. Moher D, Liberati A, Tetzlaff J, Altman DG, Group P (2009) Preferred reporting items for systematic reviews and meta-analyses: the PRISMA statement. Ann Intern Med 151(264-269):W264

5. Wright JG. Levels of Evidence and Grades of Recommendations. http:// www2.aaos.org/bulletin/apr05/fline9.asp

6. Haritinian EG, Pimpalnerkar AL (2013) Computer assisted Total knee Arthroplasty: does it make a difference? Maedica (Buchar) 8:176-181

7. Cheng T, Zhao S, Peng X, Zhang X (2012) Does computer-assisted surgery improve postoperative leg alignment and implant positioning following total knee arthroplasty? A meta-analysis of randomized controlled trials? Knee Surg Sports Traumatol Arthrosc 20:1307-1322

8. Jakopec M, Harris SJ, Rodriguez Y, Baena F, Gomes P, Cobb J, Davies BL (2001) The first clinical application of a "hands-on" robotic knee surgery system. Comput Aided Surg 6:329-339

9. Jacofsky DJ, Allen M (2016) Robotics in Arthroplasty: a comprehensive review. J Arthroplast 31:2353-2363

10. Siebert W, Mai S, Kober R, Heeckt PF (2002) Technique and first clinical results of robot-assisted total knee replacement. Knee 9:173-180 
11. Park SE, Lee CT (2007) Comparison of robotic-assisted and conventional manual implantation of a primary total knee arthroplasty. J Arthroplast 22: 1054-1059

12. Koulalis D, O'Loughlin PF, Plaskos C, Kendoff D, Cross MB, Pearle AD (2011) Sequential versus automated cutting guides in computer-assisted total knee arthroplasty. Knee 18:436-442

13. Kayani B, Konan S, Pietrzak JRT, Haddad FS (2018) latrogenic bone and soft tissue trauma in robotic-arm assisted Total knee Arthroplasty compared with conventional jig-based Total knee Arthroplasty: a prospective cohort study and validation of a new classification system. J Arthroplast 33:2496-2501

14. Kayani B, Konan S, Tahmassebi J, Pietrzak JRT, Haddad FS (2018) Roboticarm assisted total knee arthroplasty is associated with improved early functional recovery and reduced time to hospital discharge compared with conventional jig-based total knee arthroplasty: a prospective cohort study. Bone Joint J 100-B:930-937

15. Parratte S, Price AJ, Jeys LM, Jackson WF, Clarke HD (2019) Accuracy of a new robotically assisted technique for Total knee Arthroplasty: a cadaveric study. J Arthroplast 34:2799-2803

16. Anderson KC, Buehler KC, Markel DC (2005) Computer assisted navigation in total knee arthroplasty: comparison with conventional methods. J Arthroplast 20:132-138

17. Bathis H, Perlick L, Tingart M, Luring C, Zurakowski D, Grifka J (2004) Alignment in total knee arthroplasty. A comparison of computer-assisted surgery with the conventional technique. J Bone Joint Surg (Br) 86:682-687

18. Baumbach JA, Willburger R, Haaker R, Dittrich M, Kohler S (2016) 10-year survival of navigated versus conventional TKAs: a retrospective study. Orthopedics 39:S72-S76

19. Bolognesi M, Hofmann A (2005) Computer navigation versus standard instrumentation for TKA: a single-surgeon experience. Clin Orthop Relat Res 440:162-169

20. Chin PL, Yang KY, Yeo SJ, Lo NN (2005) Randomized control trial comparing radiographic total knee arthroplasty implant placement using computer navigation versus conventional technique. J Arthroplast 20:618-626

21. Decking R, Markmann Y, Fuchs J, Puhl W, Scharf HP (2005) Leg axis after computer-navigated total knee arthroplasty: a prospective randomized trial comparing computer-navigated and manual implantation. J Arthroplast 20: 282-288

22. Dutton AQ, Yeo SJ, Yang KY, Lo NN, Chia KU, Chong HC (2008) Computerassisted minimally invasive total knee arthroplasty compared with standard total knee arthroplasty. A prospective, randomized study. J Bone Joint Surg Am 90:2-9

23. Ensini A, Catani F, Leardini A, Romagnoli M, Giannini S (2007) Alignments and clinical results in conventional and navigated total knee arthroplasty. Clin Orthop Relat Res 457:156-162

24. Haaker RG, Stockheim M, Kamp M, Proff G, Breitenfelder J, Ottersbach A (2005) Computer-assisted navigation increases precision of component placement in total knee arthroplasty. Clin Orthop Relat res;https://doi.org/ 10.1097/01.blo.0000150564.31880.c4152-159

25. Hernandez-Vaquero D, Suarez-Vazquez A, Sandoval-Garcia MA, NoriegaFernandez A (2010) Computer assistance increases precision of component placement in total knee arthroplasty with articular deformity. Clin Orthop Relat Res 468:1237-1241

26. Hsu RW, Hsu WH, Shen WJ, Hsu WB, Chang SH (2019) Comparison of computer-assisted navigation and conventional instrumentation for bilateral total knee arthroplasty: the outcomes at mid-term follow-up. Medicine (Baltimore) 98:e18083

27. Jenny JY, Clemens U, Kohler S, Kiefer H, Konermann W, Miehlke RK (2005) Consistency of implantation of a total knee arthroplasty with a non-imagebased navigation system: a case-control study of 235 cases compared with 235 conventionally implanted prostheses. J Arthroplast 20:832-839

28. Mihalko WM, Krackow KA (2006) Differences between extramedullary, intramedullary, and computer-aided surgery tibial alignment techniques for total knee arthroplasty. J Knee Surg 19:33-36

29. Chauhan SK, Scott RG, Breidahl W, Beaver RJ (2004) Computer-assisted knee arthroplasty versus a conventional jig-based technique. A randomised, prospective trial. J Bone Joint Surg (Br) 86:372-377

30. Clark TC, Schmidt FH (2013) Robot-assisted navigation versus computerassisted navigation in primary Total knee Arthroplasty: efficiency and accuracy. ISRN Orthop 2013:794827

31. Roberts TD, Frampton CM, Young SW (2020) Outcomes of computerassisted surgery compared with conventional instrumentation in 19,221
Total knee Arthroplasties: results after a mean of 4.5 years of follow-up. J Bone Joint Surg Am 102:550-556

32. Selvanayagam R, Kumar V, Malhotra R, Srivastava DN, Digge VK (2019) A prospective randomized study comparing navigation versus conventional total knee arthroplasty. J Orthop Surg (Hong Kong) 27:2309499019848079

33. d'Amato $M$, Ensini A, Leardini A, Barbadoro P, Illuminati A, Belvedere C (2019) Conventional versus computer-assisted surgery in total knee arthroplasty: comparison at ten years follow-up. Int Orthop 43:1355-1363

34. Petursson G, Fenstad AM, Gothesen O, Dyrhovden GS, Hallan G, Rohrl SM et al (2018) Computer-assisted compared with conventional Total knee replacement: a multicenter parallel-group randomized controlled trial. J Bone Joint Surg Am 100:1265-1274

35. Kim YH, Kim JS, Yoon SH (2007) Alignment and orientation of the components in total knee replacement with and without navigation support: a prospective, randomised study. J Bone Joint Surg Br 89:471-476

36. Goh GS, Liow MHL, Tay DK, Lo NN, Yeo SJ, Tan MH (2018) Accelerometerbased and computer-assisted navigation in Total knee Arthroplasty: a reduction in mechanical Axis outliers does not Lead to improvement in functional outcomes or quality of life when compared to conventional Total knee Arthroplasty. J Arthroplast 33:379-385

37. Ollivier M, Parratte S, Lino L, Flecher X, Pesenti S, Argenson JN (2018) No benefit of computer-assisted TKA: 10-year results of a prospective randomized study. Clin Orthop Relat Res 476:126-134

38. Todesca A, Garro L, Penna M, Bejui-Hugues J (2017) Conventional versus computer-navigated TKA: a prospective randomized study. Knee Surg Sports Traumatol Arthrosc 25:1778-1783

39. Song EK, Agrawal PR, Kim SK, Seo HY, Seon JK (2016) A randomized controlled clinical and radiological trial about outcomes of navigationassisted TKA compared to conventional TKA: long-term follow-up. Knee Surg Sports Traumatol Arthrosc 24:3381-3386

40. Ouanezar H, Franck F, Jacquel A, Pibarot V, Wegrzyn J (2016) Does computer-assisted surgery influence survivorship of cementless total knee arthroplasty in patients with primary osteoarthritis? A 10-year follow-up study. Knee Surg Sports Traumatol Arthrosc 24:3448-3456

41. Cip J, Widemschek M, Luegmair M, Sheinkop MB, Benesch T, Martin A (2014) Conventional versus computer-assisted technique for total knee arthroplasty: a minimum of 5-year follow-up of 200 patients in a prospective randomized comparative trial. J Arthroplast 29:1795-1802

42. Lin SY, Chen CH, Fu YC, Huang PJ, Lu CC, Su JY et al (2013) Comparison of the clinical and radiological outcomes of three minimally invasive techniques for total knee replacement at two years. Bone Joint J 95-B:906-910

43. Thiengwittayaporn S, Kanjanapiboonwong A, Junsee D (2013) Midterm outcomes of electromagnetic computer-assisted navigation in minimally invasive total knee arthroplasty. J Orthop Surg Res 8:37

44. Lutzner J, Dexel J, Kirschner S (2013) No difference between computer-assisted and conventional total knee arthroplasty: five-year results of a prospective randomised study. Knee Surg Sports Traumatol Arthrosc 21:2241-2247

45. Tolk JJ, Koot HW, Janssen RP (2012) Computer navigated versus conventional total knee arthroplasty. J Knee Surg 25:347-352

46. Harvie P, Sloan K, Beaver RJ (2012) Computer navigation vs conventional total knee arthroplasty: five-year functional results of a prospective randomized trial. J Arthroplast 27(667-672):e661

47. Hoppe S, Mainzer JD, Frauchiger L, Ballmer PM, Hess R, Zumstein MA (2012) More accurate component alignment in navigated total knee arthroplasty has no clinical benefit at 5-year follow-up. Acta Orthop 83:629-633

48. Seon JK, Park SJ, Lee KB, Li G, Kozanek M, Song EK (2009) Functional comparison of total knee arthroplasty performed with and without a navigation system. Int Orthop 33:987-990

49. Kim YH, Park JW, Kim JS (2018) 2017 Chitranjan S. Ranawat award: does computer navigation in knee Arthroplasty improve functional outcomes in Young patients? A randomized study. Clin Orthop Relat Res 476:6-15

50. Dyrhovden GS, Fenstad AM, Furnes O, Gothesen O (2016) Survivorship and relative risk of revision in computer-navigated versus conventional total knee replacement at 8-year follow-up. Acta Orthop 87:592-599

51. de Steiger RN, Liu YL, Graves SE (2015) Computer navigation for total knee arthroplasty reduces revision rate for patients less than sixty-five years of age. J Bone Joint Surg Am 97:635-642

52. Antonios JK, Korber S, Sivasundaram L, Mayfield C, Kang HP, Oakes DA et al (2019) Trends in computer navigation and robotic assistance for total knee arthroplasty in the United States: an analysis of patient and hospital factors. Arthroplast Today 5:88-95 
53. Yang HY, Seon JK, Shin YJ, Lim HA, Song EK (2017) Robotic Total knee Arthroplasty with a cruciate-retaining implant: a 10-year follow-up study. Clin Orthop Surg 9:169-176

54. Kim YH, Yoon SH, Park JW (2020) Does robotic-assisted TKA result in better outcome scores or long-term survivorship than conventional TKA? A randomized, controlled trial. Clin Orthop Relat Res 478:266-275

55. Jeon SW, Kim KI, Song SJ (2019) Robot-assisted Total knee Arthroplasty does not improve long-term clinical and radiologic outcomes. J Arthroplast 34: 1656-1661

56. Cho KJ, Seon JK, Jang WY, Park CG, Song EK (2019) Robotic versus conventional primary total knee arthroplasty: clinical and radiological longterm results with a minimum follow-up of ten years. Int Orthop 43:1345-1354

57. Song EK, Seon JK, Yim JH, Netravali NA, Bargar WL (2013) Robotic-assisted TKA reduces postoperative alignment outliers and improves gap balance compared to conventional TKA. Clin Orthop Relat Res 471:118-126

58. Song EK, Seon JK, Park SJ, Jung WB, Park HW, Lee GW (2011) Simultaneous bilateral total knee arthroplasty with robotic and conventional techniques: a prospective, randomized study. Knee Surg Sports Traumatol Arthrosc 19:1069-1076

59. Smith AF, Eccles CJ, Bhimani SJ, Denehy KM, Bhimani RB, Smith LS et al (2019) Improved patient satisfaction following robotic-assisted Total knee Arthroplasty. J Knee Surg. https://doi.org/10.1055/s-0039-1700837

60. Marchand RC, Sodhi N, Khlopas A, Sultan AA, Harwin SF, Malkani AL et al (2017) Patient satisfaction outcomes after robotic arm-assisted Total knee Arthroplasty: a short-term evaluation. J Knee Surg 30:849-853

61. Liow MHL, Goh GS, Wong MK, Chin PL, Tay DK, Yeo SJ (2017) Roboticassisted total knee arthroplasty may lead to improvement in quality-of-life measures: a 2-year follow-up of a prospective randomized trial. Knee Surg Sports Traumatol Arthrosc 25:2942-2951

62. Cheng $T$, Zhang $G$, Zhang $X$ (2011) Imageless navigation system does not improve component rotational alignment in total knee arthroplasty. J Surg Res 171:590-600

63. Panjwani TR, Mullaji A, Doshi K, Thakur H (2019) Comparison of functional outcomes of computer-assisted vs conventional Total knee Arthroplasty: a systematic review and meta-analysis of high-quality, prospective studies. J Arthroplast 34:586-593

64. Lee WC, Kwan YH, Chong HC, Yeo SJ (2017) The minimal clinically important difference for knee society clinical rating system after total knee arthroplasty for primary osteoarthritis. Knee Surg Sports Traumatol Arthrosc 25:3354-3359

65. Ren Y, Cao S, Wu J, Weng X, Feng B (2019) Efficacy and reliability of active robotic-assisted total knee arthroplasty compared with conventional total knee arthroplasty: a systematic review and meta-analysis. Postgrad Med J 95:125-133

66. Li CH, Chen TH, Su YP, Shao PC, Lee KS, Chen WM (2008) Periprosthetic femoral supracondylar fracture after total knee arthroplasty with navigation system. J Arthroplast 23:304-307

67. Ossendorf C, Fuchs B, Koch P (2006) Femoral stress fracture after computer navigated total knee arthroplasty. Knee 13:397-399

68. Owens RF Jr, Swank ML (2010) Low incidence of postoperative complications due to pin placement in computer-navigated total knee arthroplasty. J Arthroplast 25:1096-1098

69. Sparmann M, Wolke B, Czupalla H, Banzer D, Zink A (2003) Positioning of total knee arthroplasty with and without navigation support. A prospective, randomised study. J Bone Joint Surg (Br) 85:830-835

\section{Publisher's Note}

Springer Nature remains neutral with regard to jurisdictional claims in published maps and institutional affiliations.

\section{Submit your manuscript to a SpringerOpen ${ }^{\circ}$ journal and benefit from:}

- Convenient online submission

- Rigorous peer review

- Open access: articles freely available online

- High visibility within the field

- Retaining the copyright to your article

Submit your next manuscript at $\boldsymbol{\nabla}$ springeropen.com 